\title{
QUANTITATIVE ANGIOGRAPHIC ASSESSMENT OF CORONARY ANASTOMOSES PERFORMED WITHOUT CARDIOPULMONARY BYPASS
}

Nancy C. Poirier, MD

Michel Carrier, MD $^{\mathrm{a}}$

Jacques Lespérance, $\mathrm{MD}^{\mathrm{b}}$

Gilles Côté, MD

Michel Pellerin, MD

Louis P. Perrault, MD, $\mathrm{PhD}^{\mathrm{a}}$

L. Conrad Pelletier, MD
Background: The quality of the anastomosis performed during coronary artery bypass grafting without cardiopulmonary bypass is a current concern, and myocardial wall restraining devices have been designed to optimize results. A quantitative angiographic analysis was performed to assess coronary anastomoses performed on beating hearts. Methods: We studied 34 patients who underwent coronary artery bypass grafting without cardiopulmonary bypass between February 1996 and April 1997. The left internal thoracic artery was anastomosed to the left anterior descending coronary artery in all patients. Coronary angiograms were performed $4 \pm 2$ days after the operation. The diameter of the anastomoses was quantified by computer-assisted analysis of grafts and native coronary arteries at the toe and heel of the anastomosis. Results: Five of the patients who underwent coronary artery bypass without a stabilizer $(n=20)$ had stenoses of the internal thoracic artery grafted to the left anterior descending coronary artery of more than $50 \%$ at the level of the anastomosis proper, 3 had stenoses at the heel of the coronary anastomosis, and 5 had stenoses at the toe. One of the patients in whom a stabilizer was used $(n=14)$ had a stenosis of more than $50 \%$ at the anastomosis, and 1 had stenosis at the heel. Eight patients in whom the anastomoses were performed without stabilization $(8 / 20,40 \%)$ had stenoses of more than $50 \%$, whereas there was only 1 stenosis of more than $50 \%$ of coronary luminal diameter among the patients in whom the operation was performed with a stabilizer $(P=.02)$. Conclusion: The quantitative angiographic evaluation suggests that left internal thoracic artery graft to left anterior descending coronary artery anastomoses have a lesser degree of intraluminal stenosis when performed with the use of a myocardial wall stabilizer. (J Thorac Cardiovasc Surg 1999; 117:292-7)
A lthough coronary artery bypass grafting (CABG) without the use of cardiopulmonary bypass and cardioplegic arrest of the heart was recently publicized in the literature, a great concern remains among cardiac surgeons regarding the quality of the surgical anastomoses performed on the beating heart. ${ }^{1-4}$ Mechanical stabilization of the myocardial wall has therefore been

From the Departments of Surgery and Radiology ${ }^{\mathrm{b}}$ and the Cardiac Catheterization Laboratory, ${ }^{c}$ Montreal Heart Institute, Montreal.

Received for publication March 12, 1998; revisions requested June 12, 1998; revisions received Aug 26, 1998; accepted for publication Sept 18, 1998.

Address for reprints: Michel Carrier, MD, Montreal Heart Institute, 5000 Belanger St E, Montreal, Quebec H1T 1C8, Canada.

Copyright $($ C 1999 by Mosby, Inc.

$0022-5223 / 99 \$ 8.00+0 \quad \mathbf{1 2 / 1 / 9 4 6 4 4}$ proposed to improve the quality of anastomoses. ${ }^{5}$ The objective of this study was to assess, by means of early quantitative angiographic evaluation, coronary anastomoses performed with and without a myocardial wall stabilizer device during CABG on beating hearts.

\section{Patients and methods}

Study patients. Between February 1996 and April 1997, 34 nonrandom, selected patients underwent $\mathrm{CABG}$ without cardiopulmonary bypass at the Montreal Heart Institute and gave informed consent for an angiographic evaluation of coronary anastomoses during the immediate postoperative period. The first 20 patients underwent CABG on beating hearts without a myocardial wall stabilizing device; in the remaining patients, a restraining or stabilizer device was used to help perform the anastomoses (Table I).

CABG was performed through a median sternotomy in 17 patients and through a left anterior minithoracotomy in 3 
patients who underwent coronary anastomosis without a stabilizing device. The operation was performed through a median sternotomy in 13 patients and through a thoracotomy in 1 patient when a stabilizer was used. All patients had a left internal thoracic artery (ITA) graft to the left anterior descending coronary artery, and patients operated on through a median sternotomy had additional ITA and saphenous vein grafts.

CABG without stabilizing device. The left anterior descending coronary artery was isolated and occluded with silicone elastomer (Silastic; Dow Corning, Midland, Mich) string snares and intracoronary occluders. The coronary anastomosis was done with a continuous suture of Prolene (Ethicon, Inc, Somerville, NJ). The immediate patency was confirmed through Doppler assessment of graft blood flow.

CABG with a stabilizing device. A simple mechanical myocardial wall restraining device, consisting of 2 small plates of metal compressing a small area of the myocardium surrounding a coronary artery, was developed locally and applied to a standard chest retractor. The edges of the stabilizer were applied along the coronary artery, after occlusion with silicone elastomer snares, causing restriction of heart movement between the $\mathrm{U}$ legs of the device. The restraining device allowed coronary anastomoses to be performed with the standard suturing technique.

Quantitative angiographic evaluation. Coronary angiography was performed $4 \pm 2$ days after CABG with a standard technique through the femoral route. A dose of $0.3 \mathrm{mg}$ nitroglycerin was injected selectively in each bypass graft. For each anastomotic site, the incidence that revealed the severest degree of stenosis was analyzed quantitatively with a computer-assisted method ${ }^{6,7}$ by means of the Cardiovascular Measurement System (CMS, version 2.0; Medical Imaging System, Nuenen, The Netherlands). A selected cinematic frame was digitized, displayed on a video monitor, and magnified 2.3 times. An automatic edge-detection program determined the graft and coronary artery contours by assessing brightness along scan lines perpendicular to the center lines of the vessel. The image was calibrated on the basis of the known or measured size of the catheter, and the vessel diameters (in millimeters) were displayed for the length of the segment analyzed. The computer automatically calculated minimum lumen diameter and percentage diameter stenosis.

The quantitative evaluation focused on 3 particular segments of interest: the native coronary artery at the proximal portion of the anastomosis (the heel, Fig 1), the anastomosis proper (Fig 2), and the coronary artery at the distal portion of the anastomosis (the toe, Fig 3). The adjacent native coronary segments were used as references. The degree of stenosis of the anastomosis proper was calculated by comparing the diameter of the anastomosis with that of the proximal portion of the graft. The normal diameter of the coronary artery proximal to the anastomosis was compared with the minimum lumen diameter of the proximal portion of the anastomosis to give the degree of stenosis of the coronary artery at the heel of the anastomosis. Similarly, the normal diameter of the coronary artery distal to the anastomosis and the minimum
Table I. Patient characteristics

\begin{tabular}{lccc}
\hline & $\begin{array}{c}\text { Without } \\
\text { stabilizer } \\
(n=20)\end{array}$ & $\begin{array}{c}\text { With } \\
\text { stabilizer } \\
(n=14)\end{array}$ & $\mathrm{P}$ \\
\hline Mariable & $17: 3$ & $10: 4$ & .2 \\
Average age (y) & $57 \pm 9$ & $61 \pm 10$ & .3 \\
LVEF <40\% & 2 & 3 & .9 \\
Left main stenosis & 0 & 1 & - \\
One-vessel disease & 7 & 1 & - \\
Two-vessel disease & 9 & 9 & - \\
Three-vessel disease & 4 & 4 &
\end{tabular}

Data expressed in numbers of patients (except for age, which is mean \pm standard deviation). $L V E F$, Left ventricular ejection fraction.

lumen diameter at the distal portion of the anastomosis were compared to estimate the degree of stenosis of the coronary artery at the toe of the anastomosis. Blood flow through these anastomoses was evaluated semiquantitatively according to the criteria previously described in the Thrombolysis in Myocardial Infarction (TIMI) studies. ${ }^{8}$

Statistical analysis. Data were analyzed with the Student $t$ test for continuous variables and with the $\chi^{2}$ or Fisher exact test for discontinuous variables. The Mann-Whitney $U$ test was used in the analysis of data that were not normally distributed. Analyses were performed with the NCSS 6.0 program (NCSS, Kaysville, Utah). Data were expressed as mean \pm standard deviation. The degree of intraluminal stenosis was expressed in 4 categories: no stenosis, stenosis between $1 \%$ and $25 \%$, stenosis between $26 \%$ and $50 \%$, and hemodynamic significant stenosis (more than $50 \%$ of the luminal diameter).

\section{Results}

Quantitative angiographic evaluation. Five patients who underwent CABG of the left ITA to the left anterior descending coronary artery without stabilizer use had residual anastomotic stenoses of more than $50 \%$ of the luminal diameter, 3 had such stenoses at the heel of the anastomosis, and 5 had such stenoses at the toe (Table II). One patient in whom the anastomosis was performed with the help of a stabilizer had a residual anastomosis stenosis of more than 50\% of the luminal diameter, one had such a stenosis at the heel of the anastomosis, and none had any stenoses at the toe. Anastomotic stenoses of more than 50\% in luminal diameter were more common among patients operated on without a stabilizer (Table II). There were 2 occlusions in the group without stabilizer use but none in the group with stabilizer use. Reference diameters of the left anterior descending coronary artery averaged $2 \pm$ $0.5 \mathrm{~mm}$ in patients without stabilizer use and $2 \pm 0.2$ $\mathrm{mm}$ in those with stabilizer use $(P=.9)$.

The anastomoses were divided according to most im- 


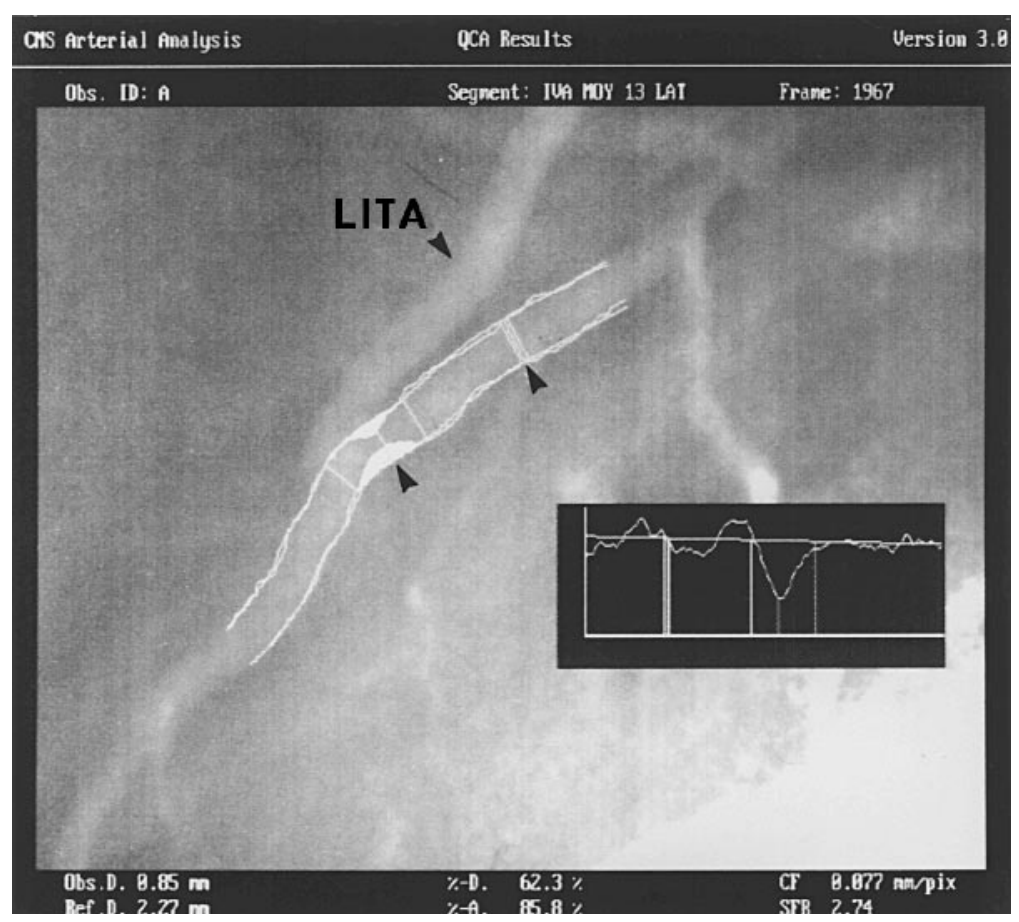

Fig 1. Quantitative angiography of a left ITA graft (LITA) to a left anterior descending coronary artery. Lateral view of a $63 \%$ stenosis of the heel of the coronary anastomosis. First arrow, Normal diameter of the coronary artery; second arrow, stenosis at the heel.

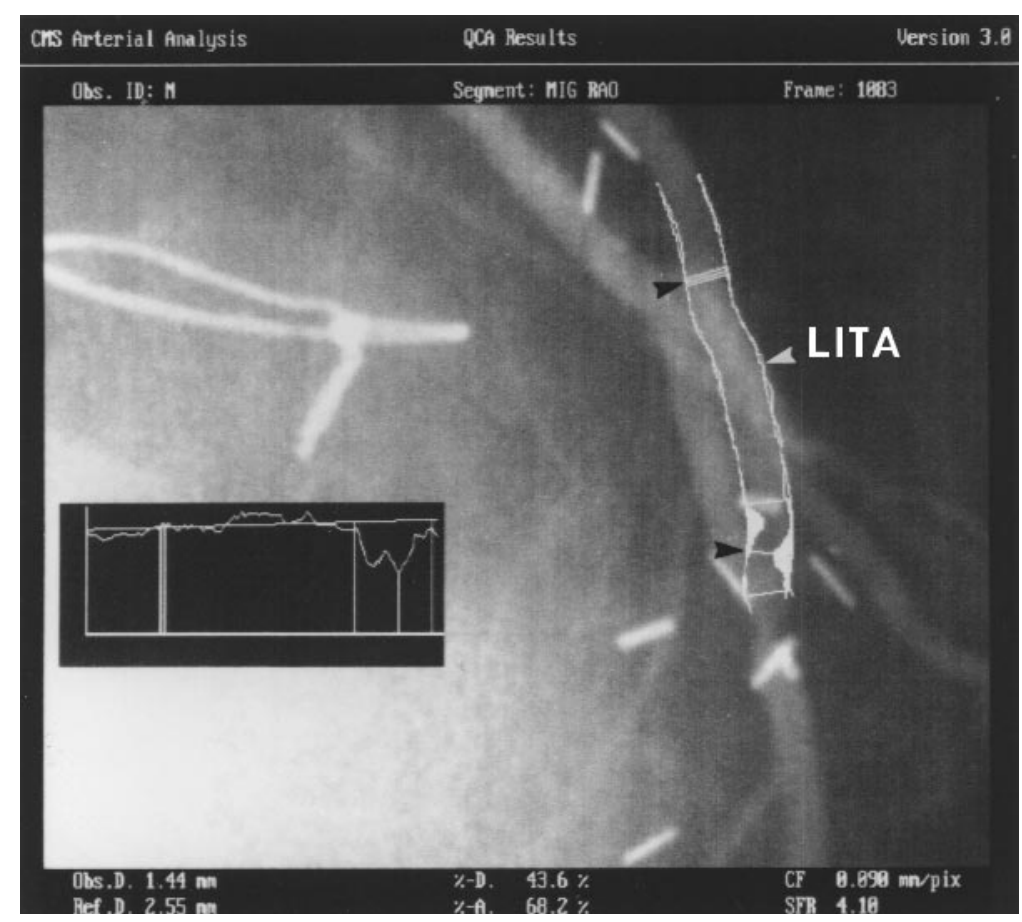

Fig 2. Quantitative angiography of a left ITA graft (LITA) to a left anterior descending coronary artery. Right anterior oblique view of a $44 \%$ stenosis of the coronary anastomosis proper. First arrow, Diameter of the ITA graft; second arrow, stenosis of the anastomosis proper. 


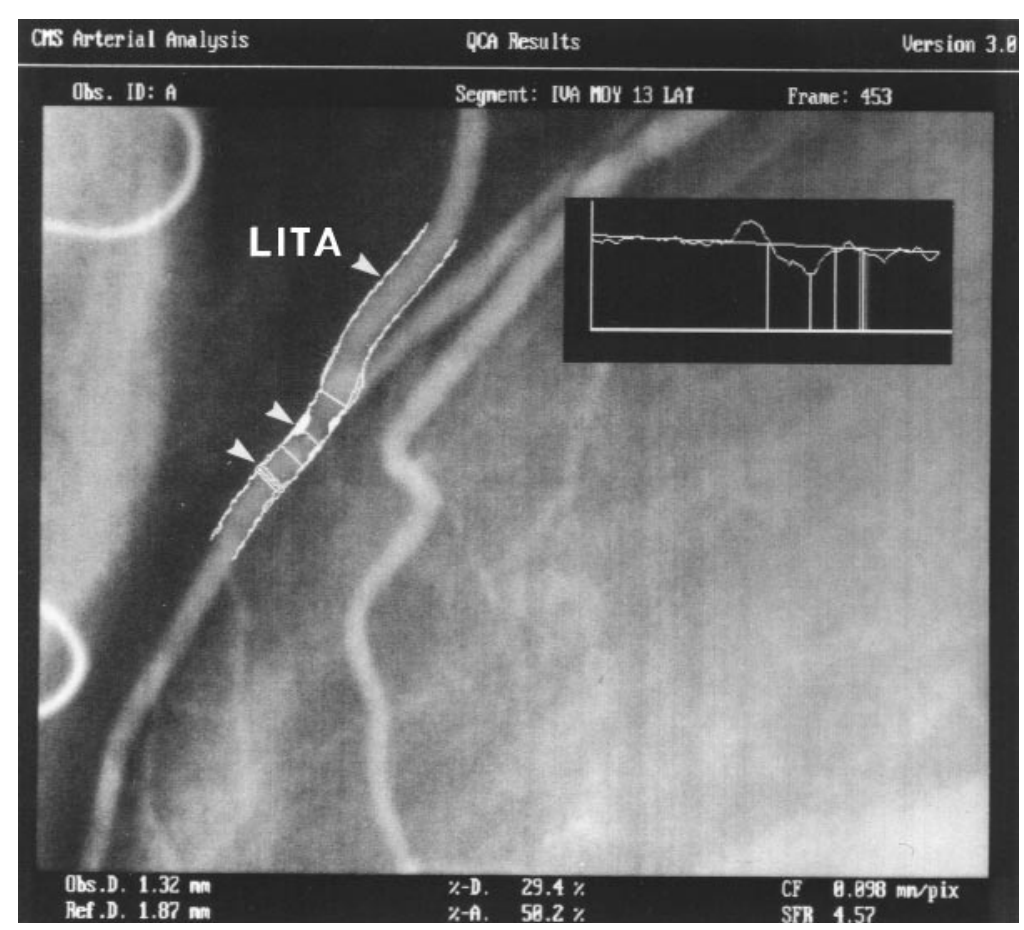

Fig 3. Quantitative angiography of a left ITA graft (LITA) to a left anterior descending coronary artery. Lateral view of a $29 \%$ stenosis of the toe of the coronary anastomosis. First arrow, stenosis at the toe; second arrow, normal diameter of the coronary artery.

portant residual stenosis, defined as the stenosis determining flow through the coronary anastomosis (Table III). Eight patients in whom the anastomosis was performed without a stabilizer had stenoses of more than $50 \%$, versus only 1 of those who underwent $\mathrm{CABG}$ with a stabilizer $(P=.007)$.

Nineteen saphenous vein grafts were used for CABG to the right $(n=9)$, the posterior descending $(n=4)$, the circumflex $(n=4)$, and the diagonal $(n=2)$ coronary arteries. Seven anastomoses were performed without a stabilizer and 12 were performed with the device. The numbers of stenoses of more than 50\% among saphenous vein grafts were similar in groups with and without stabilizer use (Table IV).

Clinical results. Patients who underwent CABG with a stabilizer had a greater number of CABGs than did the first group of patients (Table V). Total operative times were similar in the 2 groups, but ischemic time associated with anastomosis of the left ITA to the anterior descending coronary artery was slightly shorter in patients in whom a stabilizer was used, although not significantly so. Percutaneous dilatation of an occluded anastomosis in 1 patient and of the native coronary artery in another was successful in the 2 patients in whom the left ITA to the left anterior descending coro- nary anastomosis was occluded. There was no hospital death. An increase in serum creatine kinase MB levels after the operation suggested a myocardial infarction in 2 patients, both in the group without stabilizer use.

\section{Discussion}

Few authors have reported early postoperative angiographic results after revascularization of the beating heart with or without a mechanical restraining device. Buffalo and associates ${ }^{2}$ compared, in a nonrandomized study, early angiographic results of the left ITA graft to the left anterior descending coronary artery in 60 patients performed with or without cardiopulmonary bypass. Ninety-three percent of coronary anastomoses were patent in both groups. Benetti and colleagues ${ }^{3}$ also studied a similar group of 54 patients (72 saphenous vein grafts and 24 ITA grafts) with angiograms obtained during the first month after the operation. They reported patency rates of $93 \%$ with saphenous vein grafts and $88 \%$ with ITA grafts. Fanning and coworkers ${ }^{4}$ reported angiographic results in 20 patients who underwent reoperation for CABG without cardiopulmonary bypass. Angiography was performed for recurrent chest pain 2 weeks to 108 months after the operation, and 18 of the 20 studied grafts were patent. 
Table II. Quantitative angiographic results of left ITA graft to left anterior descending coronary artery

\begin{tabular}{|c|c|c|c|}
\hline Variable & $\begin{array}{c}\text { Without } \\
\text { stabilizer } \\
(n=20)\end{array}$ & $\begin{array}{c}\text { With } \\
\text { stabilizer } \\
(n=14)\end{array}$ & $\mathrm{P}$ \\
\hline \multicolumn{4}{|l|}{ Coronary anastomoses } \\
\hline No stenosis & 8 & 12 & .046 \\
\hline $1 \%-25 \%$ stenosis & 2 & 1 & \\
\hline $26 \%-50 \%$ stenosis & 5 & 0 & \\
\hline $51 \%-100 \%$ stenosis & 5 & 1 & \\
\hline TIMI 0 and $1 *$ & 1 & 0 & .5 \\
\hline \multicolumn{4}{|c|}{ Proximal anastomoses (heel) } \\
\hline No stenosis & 14 & 12 & .3 \\
\hline $1 \%-25 \%$ stenosis & 0 & 1 & \\
\hline $26 \%-50 \%$ stenosis & 3 & 0 & \\
\hline $51 \%-100 \%$ stenosis & 3 & 1 & \\
\hline TIMI 0 and $1 *$ & 1 & 0 & .5 \\
\hline \multicolumn{4}{|l|}{ Distal anastomoses (toe) } \\
\hline No stenosis & 9 & 9 & .09 \\
\hline $1 \%-25 \%$ stenosis & 1 & 3 & \\
\hline $26 \%-50 \%$ stenosis & 5 & 2 & \\
\hline $51 \%-100 \%$ stenosis & 5 & 0 & \\
\hline TIMI 0 and $1 *$ & 2 & 0 & .4 \\
\hline
\end{tabular}

Data reflect numbers of patients. TIMI, Thrombolysis in Myocardial Infarction study.

*Thrombolysis in Myocardial Infarction study (TIMI) flow categories: 0 , complete obstruction to flow; 1 , antegrade flow that incompletely opacifies the vessel beyond an obstruction; 2, permeable vessel with slower filling or clearance of contrast material; 3 , normal flow.

Table III. Quantitative angiographic evaluation of the flow-limiting stenosis: Left ITA graft to left anterior descending coronary artery

\begin{tabular}{lcc}
\hline $\begin{array}{l}\text { Flow-limiting } \\
\text { stenosis }\end{array}$ & $\begin{array}{c}\text { Without stabilizer } \\
(n=20)\end{array}$ & $\begin{array}{c}\text { With stabilizer } \\
(n=14)\end{array}$ \\
\hline 0 & 0 & 7 \\
$1 \%-25 \%$ & 2 & 1 \\
$26 \%-50 \%$ & 10 & 5 \\
$51 \%-75 \%$ & 6 & 1 \\
$76 \%-100 \%$ & 2 & 0
\end{tabular}

Data are expressed as numbers of patients; $P=.007$ between groups with and without stabilizer.

Subramanian $^{5}$ recently reported a study of 156 patients who underwent CABG through a minithoracotomy or a subxiphoid incision with a mechanical stabilizer similar to that used in this study. Ninety-two percent of the grafts were patent 24 to 36 hours after the operation. Cremer and colleagues ${ }^{9}$ also reported early postoperative angiographic results for 15 patients with the same technique through a minithoracotomy, with no graft occlusion.

This study used a more precise angiographic evalua-
Table IV. Quantitative angiographic evaluation of saphenous vein grafts

\begin{tabular}{lccc}
\hline & $\begin{array}{c}\text { Without } \\
\text { stabilizer } \\
(n=7)\end{array}$ & $\begin{array}{c}\text { With } \\
\text { stabilizer } \\
(n=12)\end{array}$ & $\mathrm{P}$ \\
Variable & & & \\
\hline Coronary anastomoses & 6 & 10 & .7 \\
$\quad$ No stenosis & 0 & 0 & \\
$1 \%-25 \%$ stenosis & 1 & 1 & \\
$26 \%-50 \%$ stenosis & 0 & 1 & .3 \\
$51 \%-100 \%$ stenosis & & & \\
Proximal anastomoses (heel) & 6 & 8 & \\
No stenosis & 0 & 0 & \\
$1 \%-25 \%$ stenosis & 1 & 1 & \\
$26 \%-50 \%$ stenosis & 0 & 3 & \\
$51 \%-100 \%$ stenosis & & & \\
Distal anastomoses (toe) & 3 & 6 & \\
No stenosis & 2 & 3 & \\
$1 \%-25 \%$ stenosis & 2 & 2 & \\
$26 \%-50 \%$ stenosis & 0 & 1 & \\
$51 \%-100 \%$ stenosis & & & \\
\hline
\end{tabular}

Data reflect numbers of patients.

Table V. Operative data

\begin{tabular}{lccc}
\hline Variable & $\begin{array}{c}\text { Without } \\
\text { stabilizer } \\
(n=20)\end{array}$ & $\begin{array}{c}\text { With } \\
\text { stabilizer } \\
(n=14)\end{array}$ & $\mathrm{P}$ \\
\hline Grafts per patient & $1.4 \pm 0.5$ & $2.3 \pm 0.7$ & .0002 \\
Operative time (min) & $143 \pm 30$ & $133 \pm 27$ & .3 \\
Ischemic time of LAD & $20 \pm 7$ & $16 \pm 8$ & .2 \\
$\quad$ anastomosis* (min) & 2 & 0 & .5 \\
Myocardial infarction & 2 & 0 & .5 \\
Reintervention (PTCA) & 0 & 0 & - \\
Stroke & 0 & 0 & - \\
In-hospital deaths & & & - \\
\hline
\end{tabular}

Data expressed as numbers of patients or mean \pm standard deviation as appropriate. $L A D$, Left anterior descending coronary artery; PTCA, percutaneous transluminal coronary angioplasty.

*Time of occlusion of the left anterior descending coronary artery during coronary anastomosis.

tion of coronary anastomoses than used in previous reports, namely a quantitative approach. Although these patients were the first in our experience to undergo CABG on the beating heart, the use of a stabilizer resulted in a significant decrease in residual anastomotic stenosis, as expressed in percentage of control arterial diameter, in a lower number of residual anastomotic stenosis of more than $50 \%$, and in a better coronary blood flow through the anastomoses. Consequently, left ITA graft to left anterior descending coronary artery anastomoses should be performed with the help of a mechanical restraining device. Moreover, these results compare favorably with recent experiences published 
for early angiographic evaluation of CABGs performed with the classic approaches featuring cardiopulmonary bypass and cardioplegic arrest. ${ }^{10,11}$

Cardiac stabilization with one of the many restraining devices currently in use offers a major technical advantage by creating a small but stable coronary field in which to perform the anastomosis during a short period of regional ischemia. Although these devices are easy to use on the anterior surface of the heart, they are far more difficult to position correctly for circumflex coronary artery and in distal right coronary artery territories. This may explain the similar numbers of anastomotic stenoses observed in saphenous vein grafts performed with and without stabilizer use.

This study describes early results of a small, consecutive, nonrandom sample of patients in whom the operation was performed through a median sternotomy or a minithoracotomy. Although these patients were among our initial experience with CABG on the beating heart and represent our learning curve with the techniques, quantitative analysis of coronary angiograms at anastomotic sites yields a useful appreciation of angiographic results with the 2 techniques.

The techniques of minimally invasive $\mathrm{CABG}$ are rapidly evolving and are most promising. Quantitative angiographic evaluation of coronary anastomoses appears to be an appropriate tool to study the development of these approaches. ${ }^{5,6,12}$ This study shows that, during CABG on the beating heart, grafting of ITA to the left anterior descending coronary artery performed with the help of a mechanical myocardial wall restraining device results in lesser residual luminal stenosis at the anastomotic site than does the same procedure performed without stabilization. Myocardial stabilizers appear useful in obtaining optimal technical results in minimally invasive CABG.

\section{REFERENCES}

1. Benetti FJ. Coronary artery bypass without extracorporeal circulation versus percutaneous transluminal coronary angioplasty: comparison of costs [letter]. J Thorac Cardiovasc Surg 1991;102: 802-3.

2. Buffalo E, de Andrade JC, Branco JN, et al. Coronary artery bypass grafting without cardiopulmonary bypass. Ann Thorac Surg 1996;61:63-6.

3. Benetti FJ, Naselli G, Wood M, Geffner L. Direct myocardial revascularization without extracorporeal circulation: experience in 700 patients. Chest 1991;100:312-6.

4. Fanning WJ, Kakos GS, Williams TE. Reoperative coronary artery bypass grafting without cardiopulmonary bypass. Ann Thorac Surg 1993;55:486-9.

5. Subramanian VA. Less invasive arterial CABG on a beating heart. Ann Thorac Surg 1997;63:S68-71.

6. Lespérance J, Campeau L, Reiber JH, Bois M, Dyrda I, Laurier $\mathrm{J}$, et al. Validation of coronary artery saphenous vein bypass graft diameter measurements using quantitative angiography. Int $\mathbf{J}$ Card Imaging 1996;12:299-303.

7. Reiber JH, van der Zwet PM, von Land CD, et al. Quantitative coronary arteriography: equipment and technical requirements. In: Reiber JH, Serruys PW, editors. Advances in quantitative coronary arteriography. Dordrecht, The Netherlands: Kluwer Academic; 1993. p. 75-111.

8. Reiner JS, Lundergan CF, Fung A, et al. Evaluation of early TIMI 2 flow after thrombolysis for acute myocardial infarction. Circulation 1996;94:2441-6.

9. Cremer J, Strüber M, Wittwer T, et al. Off-bypass coronary bypass grafting via mini-thoracotomy using mechanical epicardial stabilization. Ann Thorac Surg 1997;63:S79-83.

10. Hoffman O, Beyssen B, Pagny JY, et al. Evaluation angiographique précoce des pontages coronaires par greffons artériels. Arch Mal Coeur 1993;86:1445-50.

11. Bergeron P, Simonetti B, Poyen V, et al. Contrôle angiographique précoce des revascularisations coronaires par artères mammaires internes: à propos d'une série consécutive et prospective de 180 pontages. Ann Chir 1991;45:82-9.

12. Blankenhorn DH, Selzer RI, Mack WJ, et al. Evaluation of colestipol/niacin therapy with computer-derived coronary endpoint measures: a comparison of different measures of treatment effects. Circulation 1992;86:1701-9. 